\title{
Economic Mining Method Evaluation for Separated Ore Lenses in Block 186 at Boliden Tara Mines, Ireland, Using Deswik Software
}

\author{
Frédéric Klose and Philipp Hartlieb \\ Chair of Mining Engineering and Mineral Economics, Department Mineral Resources Engineering, \\ Montanuniversitaet Leoben, Leoben, Austria
}

Received March 29, 2019; accepted April 6, 2019; published online April 23, 2019

\begin{abstract}
In block 186 of Boliden Tara Mines, Ireland, two ore lenses are separated by waste and low grade material. Long-hole open stoping is seen as an alternative method to room-and-pillar mining that permits the extraction of two waste-separated ore lenses simultaneously. Both methods are well-established at the mine. Within the scope of a bachelor's thesis, the viability of this method was investigated. This was done by using Deswik software, currently being introduced at the mine, to generate data for comparison. While the complexity of the situation necessitated a number of simplifications and adjustments, it is concluded that the separate mining of both ore lenses, as planned, is more economical.
\end{abstract}

Keywords: Underground mining, Deswik, Ireland, Longhole open stoping, Room-and-pillar, Return on investment

Wirtschaftlichkeitsbetrachtung von Abbaumethoden für separierte Erzlinsen in Block 186 von Boliden Tara Mines, Irland, mit Deswik-Software

Zusammenfassung: In Block 186 von Boliden Tara Mines, Irland, sind zwei Erzlinsen durch Berge und geringvererztes Nebengestein voneinander getrennt. Das Abbauverfahren des Kammerbaues mit Langbohrlöchern wird hier als eine Alternative zum Kammerpfeilerbau gesehen, die es ermöglicht, beide Linsen gleichzeitig zu fördern. Beides sind bereits langjährig etablierte Verfahren. Im Rahmen einer Bachelorarbeit wurde die Wirtschaftlichkeit dieser Methode überprüft. Für die Generierung von Daten wurde DeswikSoftware verwendet, welche derzeit in den Betrieb einge-

\footnotetext{
P. Hartlieb ( $\varangle)$

Chair of Mining Engineering and Mineral Economics, Department Mineral Resources Engineering,

Montanuniversitaet Leoben,

Franz-Josef-Strasse 18,

8700 Leoben, Austria

philipp.hartlieb@unileoben.ac.at
}

führt wird. Während die Komplexität zu Vereinfachungen und zu Adaptierungen der Betrachtung zwang, wurde festgestellt, dass der ursprünglich geplante, separate Abbau die wirtschaftlichere Variante ist.

Schlüsselwörter: Untertagebergbau, Deswik, Irland, Kammerbau, Langbohrlöcher, Kammerpfeilerbau, Kapitalrentabilität

\section{Introduction}

The Navan orebody is a carbonate-hosted, Tournaisian age deposit [1]. Ore-grade mineralization is concentrated in strata-bound lenses below argillite horizons that acted as aquitards during the formation process [2]. Due to its bedding planes, argillite is also the primary source of dilution at Tara Mines. Mineralization beneath the ore lenses is below cut-off, but homogeneously disseminated. This situation is also found in block 186 of the mine, where the thickness of the waste layer between the lenses is decreasing. In consequence, supported by the high grades expected in both lenses and the reduced need for infrastructure development, interest in the employment of the long-hole open stoping method has been generated.

\section{Mining Methods Applied}

Long-hole open stoping (LHOS) is one of two methods used by Tara Mines to adapt to the highly inhomogeneous orebody, the other being room-and-pillar (RP) mining (Fig. 1).

Due to economy of scale the long-hole open stoping method is regarded as highly economical [3]. Long-hole open stopes are categorized into primary, secondary and tertiary stopes. Acting as pillars during the extraction of the primary stopes, secondary stopes are mined once the backfilling of the adjacent primary stopes has been com- 

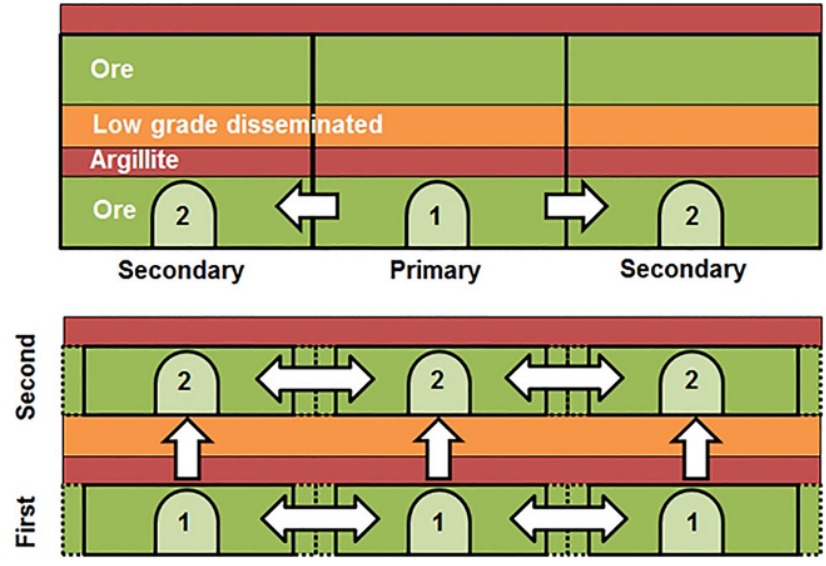

Fig. 1: Long-hole open stoping and sequencing options in the block 186 setting, depicted schematically (above) compared to the room-and-pillar method (below)

pleted. This means that more ore can potentially be extracted from a lens, but sequencing options are limited as shown in Fig. 1. Tertiary stopes host block access drifts and are not the focus of the thesis. In the case of block 186, the favorable economics of this method is hoped to offset potential losses incurred by the additional low-grade material.

The use of dedicated pillars makes the extraction sequence of room-and-pillar units independent from the backfilling of adjacent stopes and provides added flexibility for ore blending [4]. The only sequencing restriction arises when encountering two overlying lenses, as in block 186. In this case, the lower stope is mined and backfilled first. The typical drawback of dedicated pillars is that not all oregrade material is extracted from a lens, which is also true for Tara Mines [3]. Room-and-pillar mining is the method that block 186 has been originally designed for.

\section{Data Basis and Processing}

The assessment of the viability of long-hole open stoping was based on economic considerations and required data for costs and revenues.

For the cost data, figures presently used in the economic assessment of individual stopes were used. These are provided on a per unit basis by the mine, mill and accounting departments and are validated regularly.

Geological data used as input took the form of the most current lithographical surfaces and block models available for block 186, and revenue data was extracted from the block models in the form of net smelter returns. These are calculated for each block using an in-house algorithm based on assigned grades and recovery relationships affecting final metal contents of the concentrates. The total net smelter return of a stope itself is an average value calculated from the model blocks contained within.

\subsection{Deswik}

Deswik is a commercial mining software suite being introduced at Tara Mines. Its numerous features and modular setup around Deswik.CAD allows a customized application to a wide range of activities along the lifecycle of a mine.

For this project, the scheduling tool Deswik.SCHED was used to perform cost and revenue calculations and generate exportable data, in conjunction with the interactive scheduler Deswik.IS, which links Deswik.CAD and Deswik.SCHED by converting solids into schedule activities. The conversion is guided by sequencing rules and attribute constraints that mimic the sequence of mining activities and must be set up in advance.

The stope optimizer, Deswik.SO, played a particularly prominent role. It is a long-term planning tool incorporating a third-party algorithm generating optimal stope geometries subject to user-defined constraints. Cut-off values or grades, geometrical design factors, optimization framework dimensions and other geological data are required inputs and aid in maximizing the extractable value of a deposit. Reliable block model data is of especial importance. Apart from solids, Deswik.SO also generates wireframes, which indicate the geometry of the solids and for this project were considered the most important output.

\subsubsection{Deswik Application}

To compare the methods, emphasis was put on the original design locations. Deswik.SO scenario settings were adjusted to reflect stope design restrictions and a small discretization was used to allow generated shapes to follow the mineralization as indicated by the block models. The generation of shapes spanning both ore lenses and the in-between material was encouraged by matching the maximum shape heights to that of the frameworks.

The actual application of Deswik proved to be more complex than anticipated. A design line offset and two block models required the use of multiple optimization frameworks. It was also discovered that the design lines were not suitable for long-hole open stoping as practiced at the mine because stopes would either be unreasonably wide or leave unrealistically narrow pillars. To address this issue, it was decided to shift the approach from a general assessment to comparing the mining methods in principle and on an equal basis, by focusing on the dimensions of room-and-pillar units and the overlapping segments of the generated shapes.

Another concern was that no stope shapes spanning the low grade horizon were generated by Deswik.SO. This indicated that long-hole open stope units are not profitable in block 186. However, solids created manually from the wireframe outputs and interrogated against the block model did in fact exceed the cut-off. A possible explanation for this inconsistency could be that these simply did not constitute an optimum solution for the algorithm. Since solids encompassing both ore lenses were required to continue with this assessment, it was decided to continue with the manually generated shapes. 


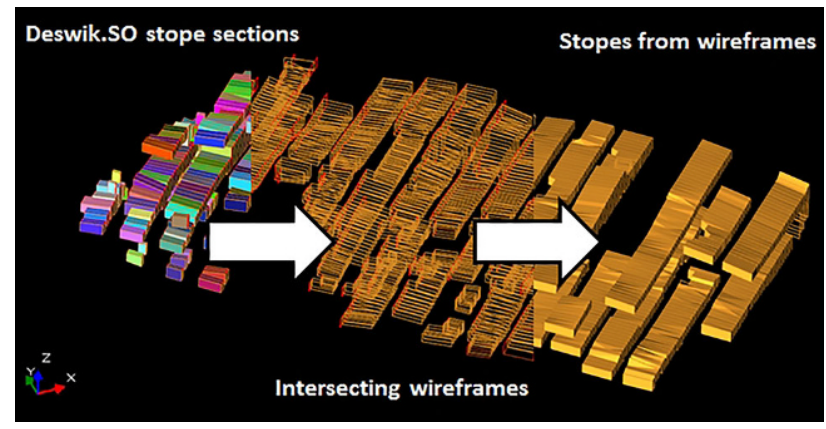

Fig. 2: Wireframes of the generated stope sections (left) intersecting the existing designs (middle) used to generate stope solids (right)

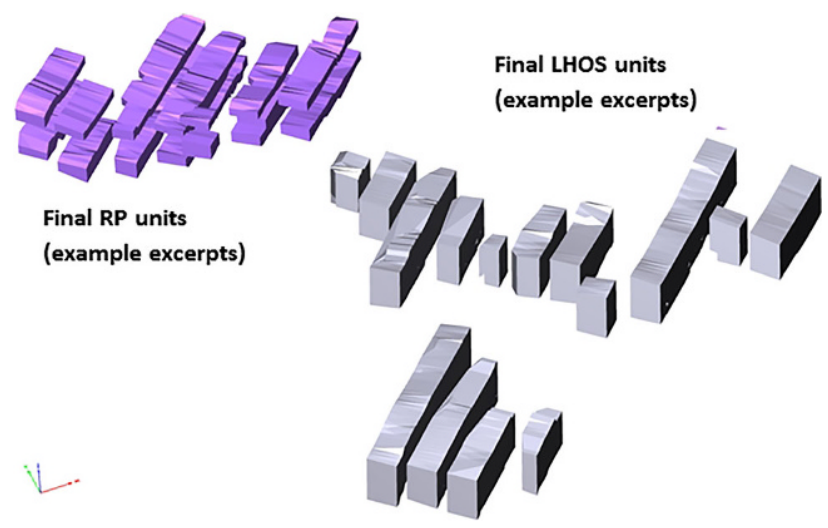

Fig. 3: Final stope shape examples for each mining method used for scheduling after removal of non-overlapping sections

Solids generated by Deswik.SO cannot immediately be converted to Deswik.SCHED activities due to the discretization and missing attributes required for scheduling. Therefore, connected solids were created for both mining methods from the wireframe outputs (Fig. 2), and missing attributes were assigned from the existing stopes. As it was discovered that the net smelter return values were dictated by a single wireframe, the solids were reinterrogated against the block model.

After reaching the final design stage (Fig. 3), a reporting sheet was set up in Deswik.SCHED for the calculation of costs and revenues. Additional attributes necessary for these calculations were imported from the solids and included net smelter return, solid length to account for the presence of drifts to calculate development costs and crusher distance for haulage costs.

\subsection{Data Adjustments}

At Tara Mines, experience-based dilution and recovery factors are applied to take into account uncertainties during production that cause final stope geometries to deviate from plan. These depend on the mining method considered and are more conservative for long-term than for shortterm planning horizons. Dilution accounts for the fact that ore grade material occurs beneath argillite. Higher dilution is expected for room-and-pillar mining because the impact of a break-in of argillite is larger on lower stope tonnages. Recovery is independent of the method involved and is dictated only by the planning horizon. Four different long-term scenarios were considered to assess the economic impact of dilution and recovery.

Deswik.SO is capable of considering dilution by extending solids vertically after the generation process. By extending the stope size, additional blocks of the geological model are included for the calculation of the final net smelter return. This option was not applied, because the discretization does not facilitate reaching a fixed dilution percentage.

Dilution and recovery rates have important implications of downstream processes by affecting stope tonnage, which is the primary foundation for total cost and revenue calculations. These were first calculated in Deswik.SCHED for each stope in an undiluted, fully recovered state. The data was then exported to Microsoft Excel, where the Deswik.SCHED calculations were reintroduced, including links to dilution and recovery factors. This enabled flexible scenario analyses through the use of the What-If functionality and allowed for the correction of a cost calculation error made in Deswik.SCHED after access to the software ended.

The adjustment of the calculated net smelter return values to dilution was performed in a similar way. As the result of an external algorithm on the basis of grades, diluted grades are required to properly calculate a diluted net smelter return. This is conflicting with the concept of dilution being a consequence of mining, which led to the decision to approximate a relationship between net smelter return and dilution using financial tools used by staff at Tara Mines for assessing individual stopes.

\section{Assessment Methodology and Results}

Mining method selection can be regarded as selecting a particular investment. This demands the use of an appropriate appraisal method. Net present value is an obvious choice, as it discounts project cash flow over time and is thereby able to consider the different extraction rates of each method [5]. Faster extraction and low risk, represented by the discounting rate, contribute to a higher net present value. Three issues prevented the application of net present value in this case.

First, block access infrastructure can be regarded as the initial investment enabling cash flow from a stope and is performed in intervals for several stopes simultaneously. This prevents a proper allocation of initial investment to individual stopes. Additionally, because the comparison is based on overlapping sections, the impact of an allocation would have been disproportionate on smaller sections.

Second, if all material contained within long-hole open stopes in block 186 is processed, the large amounts of low grade material have potentially significant negative downstream effects. To reflect the associated risks, appropriate discounting rates are necessary. However, the selection of such rates is invariably subjective [5].

The biggest obstacle was the integration of long-hole open stopes into the mining schedule. This exercise was 
Fig. 4: Return on investment for room-and-pillar and long hole open stopes for different recovery and dilution scenarios scenarios

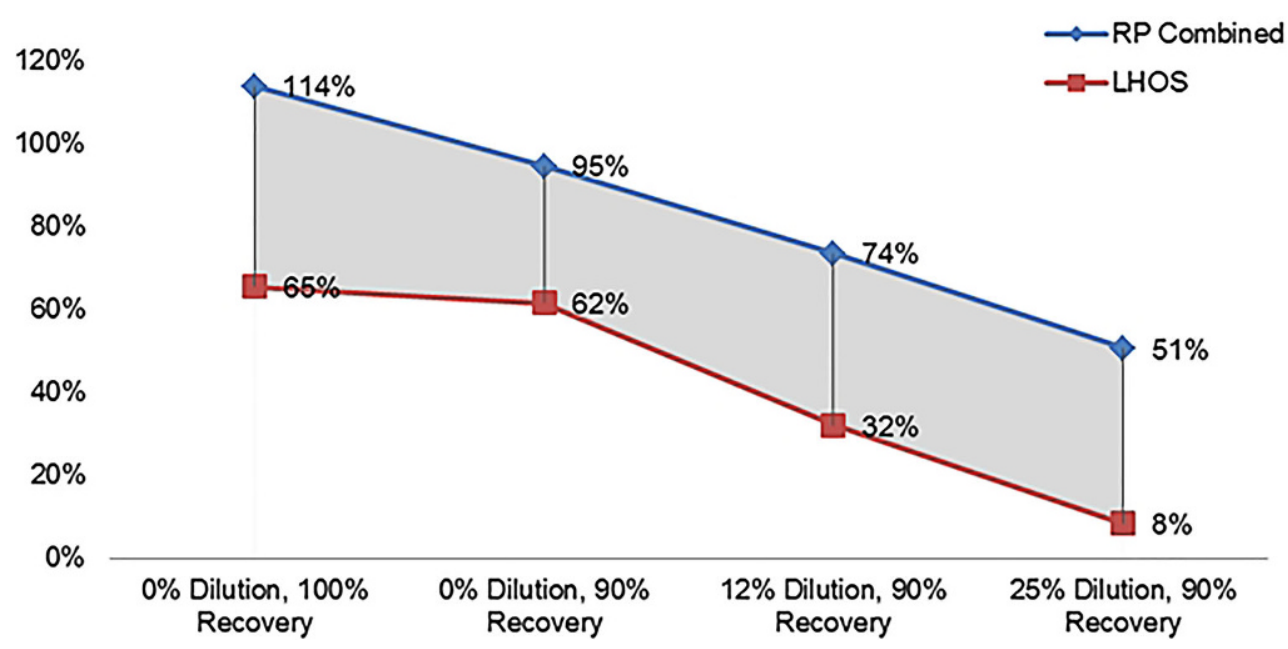

not considered feasible in the short time available, as it requires in-depth knowledge of production constraints and, in particular, observance of the different sequencing requirements for each method.

To allow for the comparison of the methods, a simple return on investment calculation was chosen as the alternative, which greatly simplified the process by allowing the summarizing of data for each method in the form of tonnage-weighted averages.

This simple calculation quickly highlights the benefits of room-and-pillar mining over long-hole open stoping in block 186 (Fig. 4). This is due to the comparably high amount of waste material that has to be mined in the latter case, having a significant negative impact on the coststructure. Due to confidentiality constraints the detailed costs, however, cannot be shown in this publication.

\section{Conclusion}

The use of specialized software such as Deswik enables tapping into the vast array of raw and processed data collected on a daily basis to help answer questions and uncover possibilities for quality improvements. As is the case with any software used as part of a decision making process, knowledge of its capabilities, limitations and sensitivities is crucial and care must be taken not to oversimplify a highly complex situation.

Within the scope of this thesis project, Deswik software was used to assess the viability of long-hole open stoping in the particular setting of block 186, where two ore lenses are separated by a horizon of low-grade material. The assessment was concluded from a simplified economic point of view. The underlying assumption is that all material contained within the solids is ultimately processed, but the actual downstream effects of increased, low-grade tonnage has not been assessed. Possible methods for the separation of ore and waste during production were not considered.
Bearing in mind the simplifications and adjustments to compare the mining methods in principle, it is concluded that using the room-and-pillar method remains the most economical option for mining both ore lenses. This is true for all scenarios, whose clear impact on profitability incentivizes exploring measures to effectively reduce or control dilution.

Acknowledgements. Boliden Tara Mines Ltd. is gratefully acknowledged for giving the opportunity to realize such a project, with particular thanks going to Mr. Paddy McConnell and Mr. Borja Arias Gutierrez of the Mine Engineering Department for their guidance and support.

Funding. Open access funding provided by Montanuniversität Leoben.

Open Access This article is distributed under the terms of the Creative Commons Attribution 4.0 International License (http://creativecommons. org/licenses/by/4.0/), which permits unrestricted use, distribution, and reproduction in any medium, provided you give appropriate credit to the original author(s) and the source, provide a link to the Creative Commons license, and indicate if changes were made.

\section{References}

1. Ashton, J.H.; Holdstock, M.P.; Geragthy, J.F.; O'Keeffe, W.G.; Martinez, N.; Peace, W.; Philcox, M.E.: The Navan Orebody-discovery and geology of the South West Extension, in: Kelly, J. G.; Andrew, C. J.; Ashton, J. H.; Boland, M. B.; Earls, G.; Fusciardi, L.; Stanley, C. (eds): Europe's Major Base Metal Deposits, Dublin: Irish Association for Economic Geology, 2003, pp 405-436

2. Ashton, J.H.; Blakeman, R.J.; Geraghty, J.F.; Beach, A.; Coller, D.; Philcox, M.E.; Boyce, A.J.; Wilkinson, J.J.: The Giant Navan Carbonate-Hosted Zn-Pb Deposit-A Review, in: Archibald, S.M.; Piercey, S.J. (eds): Current Perspectives on Zinc Deposits, Dublin: Irish Association for Economic Geology, 2010, pp 74-112

3. Hartman, H.; Mutmansky, J.: Introductory Mining Engineering, 2. ed., Hoboken, NJ: John Wiley \& Sons, 2002

4. Darling, P. (ed.): SME Mining Engineering Handbook, 3. ed., vol. 2, Littleton, CO: Society for Mining, Metallurgy and Exploration (SME), 2011

5. Torries, T. F.: Evaluating Mineral Projects: Applications and Misconceptions, Littleton, CO: Society for Mining, Metallurgy and Exploration (SME), 1998

Publisher's Note. Springer Nature remains neutral with regard to jurisdictional claims in published maps and institutional affiliations. 